\title{
Psychosocial Wellbeing and Its' Relationship with Attachment Patterns and Academic Achievement Motivation of Foster Care Children in Save Our Soul Enfants Ethiope, Burayu Orphanage Vocational Training and Production Center
}

\author{
Zenebe Demissie* \\ Psychology Department, Debire Birhan University University, PO box 247, Debire Brhan, Ethiopia \\ Habtamu Wondimu (Professor) \\ School of Psychology, Addis Ababa University, PO box 1121, Addis Ababa, Ethiopia
}

The research is financed by the researchers themselves

\section{Abstract}

The main objectives of this study is to assess the status of psychosocial wellbeing and its relationship with attachment patterns and academic achievement motivation of foster care children in Save Our Soul Enfants Ethiope, Burayu Orphanage Vocational Training and Production Center (SOS EE BOVTPC). Mixed research design was employed to achieve the research objectives. For the purpose of quantitative data 134 foster children were participated, and for the qualitative data six foster families and six foster children were participated. Those six foster families and six foster children were purposefully selected as a sample. The self-report version of the Relationship Structures questionnaire, the Strengths and Difficulties Questionnaire, the Achievement Motivation Inventory instruments, and semi-structured interview are administered. The result revealed that the majority of children have normal symptom of psychosocial wellbeing and it has relationship with their academic achievement motivation and with their anxious attachment. It was recommended that the concerned body should give emphasize for the improvement of their psychosocial wellness.

Keywords: Academic Achievement Motivation, Attachment Pattern, and Psychosocial Wellbeing

DOI: $10.7176 /$ RHSS/10-19-01

Publication date:October $31^{\text {st }} 2020$

\section{Introduction}

Children's psychosocial well-being is the appropriate age and stage; physical, social and psychological development (Bhargava, 2005). This is determined by a combination of children's capacities and their social and material environment for survival and development, especially in chronically difficult circumstances (Linda, Geoff \& Lorraine, 2006).

Researches are releasing the presence of psychosocial wellbeing among foster children. Gumede (2009) found that, lacks of formal psychosocial supports are expressed as the problem of foster children. Foster children face many psychosocial challenges that involve the lack of parental guidance, love, care, and acceptance in the new families or institution care they join (Nasaba et al., 2006). In the theories of Erik Erikson's (1950), development consists of a series of psychosocial crises which are resolved by the maturity of the individual.

When psychosocial problems occur in foster children, most of the time, different symptoms are manifested, such as experience of feelings of confusion, fear, apprehension of the unknown, loss, sadness, anxiety, loneliness, stress, etc. Such feelings and experiences must be addressed and treated early to prevent or decrease poor developmental and mental health outcomes that ultimately affect a child's educational experience and the quality of adulthood (Delilah, 2013).

For the purpose of nurturing children; protection, trust and security attachment is important. According to Roy and Kathleen (2007) "an attachment refers to the strong emotional bond that exists between an infant and his or her caretaker" (p.55). Attachment to a primary caregiver is essential to the development of emotional security and social conscience (American Academy of Pediatrics, 2009). One of the biggest challenges faced by young children in foster care is maintaining attachment with their parents. Children and parents need the opportunity to maintain an attachment and develop more positive interactions. However, visits with parents can be upsetting to young children in foster care and disruptive to other aspects of their development (American Academy of Pediatrics, 2009).

Studies on the attachment pattern indicated that if foster children encountered negative feeling form their foster parents they decrease their relationship with them (Stovall-McClough \& Dozier, 2004; and Ponciano, 2010). This may indicate their loss of securely attached up to 30 to $40 \%$ (Jacobsen et al., 2013). These insecure individuals rely on secondary attachment (Mikulincer and Shaver, 2007). In contrast, children with insecure histories are likely to view others as less available and less trustworthy and to have internalized a compromised sense of self (Janet et al., 2006). 
Academic achievement motivation is used to mean the pupil's need or drive towards the achievement of success in academic work (Amalaha, 1975; Moen and Doyle, 1977; cited in Muola, 2010). It is assumed that people differ in their need to achieve in situations that call for excellence (Gesinde, 2000; cited in Muola, 2010). A great deal of research has found that students high in academic motivation are more likely to have increased levels of academic achievement and have lower dropout rates (Muola, 2010).

In their study, Imaobong et al. (2013) revealed that level of achievement motivation has a significant impact on academic engagement of students. The presence of secured attachment has positive influence on the psychosocial wellbeing of children (Dexter et al., 2013; and NICHD, 2006). In the other side, psychosocial wellbeing of children depends significantly on the quality of attachments to their care givers (Sadock and Sadock, 2007).

Research finding on the relationship between psychosocial wellbeing and academic achievement indicated that relatively weak comparing to other dimensions (Lindeboom and colleagues, 2010).

In the Ethiopian literature on foster children's psychosocial wellbeing and its' relationship with attachment and academic achievement motivation is rare. A few researches (Afework, 2013; Mebratu et al. 2014; and Sebsibe et al. 2014) that has been carried out on HIV/ OVC (Orphan and Venerable Children) who suffers from particular social and economic disadvantages and mental health problems. Study on the foster children's psychosocial wellbeing and its' relationship with attachment and academic achievement motivation in Ethiopia is lacking. So, this study focused to fill the gap by examining foster children's psychosocial wellbeing and its' relationship with attachment and academic achievement motivation in SOS Enfants Ethiopia Burayu Orphanage and Vocational Training and Product Center.

\section{Methods and Materials}

\subsection{Description of the study area}

The study was conducted in Save Our Soul Enfants Ethiope, Burayu Orphanage Vocational Training and Production Center (SOS EE BOVTPC). SOS Enfantes Ethiope (SOSEE) is an international charitable organization which was founded by the two benevolent French nationals, Mr Yves Ferez and M/Rs Jaqulin Ferez 27 years ago in Ethiopia. Currently the organization is found in the Oromia region, Burayu-Keta woreda; which is near to Addis Ababa. The alternative cares (i.e. especially foster cares and community cares) are practiced in the then community, which found around the place where the organization is found.

\subsection{Research design}

In order to assess foster children's psychosocial wellbeing and its' relationship with attachment and academic achievement motivation, the mixed (quantitative and qualitative) research design was employed.

\subsection{Population}

The current study targeted at the children who are between 15-18 years old and found in care and support in alternative family based care, specifically who live with foster families with the support of SOS EE BOVTPC. The overall populations of the institution who get support (beneficiary) were above 433 children. Among them above 240 children are in the foster care systems who, are considered as study population. In order to select the respondents of the study, the researcher used stratified random sampling technique. The population was stratified by educational levels (first level, second level, preparatory, TVT and College; i.e. $1^{\text {st }}$ level students $=23,2^{\text {nd }}$ level $=51$, preparatory $=37$, TVT \& College $=39$ ). And also 6 ( 3 females and 3 males) foster children and 6 (all are females) foster families were taken purposely for interview. The number of the sample size for the study was determined based on the scientific sample size calculator developed by Yamane (1967). The researcher used this scientific sample size calculator because this technique was employed with a $95 \%$ confidence level and $5 \%$ degree of precisions. Totally, 134 foster children were selected as a sample.

\subsection{Measures}

To identify the psychosocial wellbeing of foster children Goodman, (1997) Strengths and Difficulties Questionnaire (SDQ) scale was adopted which consisted of 25 questions. It is a behavioral screening tool, designed for children that measures psychosocial well-being across five dimensions: (1) emotional symptoms, (2) conduct problems, (3) hyperactivity/inattention, (4) peer relationship problems, and (5) pro-social behavior. Each sub-scale has 5 items, scored on a 3 -point Likert scale $(0=$ Not True, $1=$ Somewhat True, and $2=$ Certainly True). The validity of the self-reported total difficulties scale has been assessed and confirmed in multiple contexts (Cornbrash's alpha ranging from $0.73-0.89$ ), indicating that the scale itself is internally valid.

In addition the researcher adopted Fraley et al, (2011) The Relationship Structures (ECR-RS) Questionnaire instrument for the purpose of measuring the attachment relationship of foster children with foster families of SOS EE BOVTPC. It is a self-report instrument designed to assess attachment patterns in a variety of close relationships. The items are used to assess attachment styles with respect to 4 targets (i.e., mother, father, romantic partner, and 
best friend). Each item is rated on a 7-point scale where $1=$ strongly disagree and $7=$ strongly agree. The testretest reliability of the individual scales is approximately. 65 for the domain of romantic relationships and.80 in the parent domain.

To assess the academic achievement motivation of foster children the researcher adopted the Achievement Motivation Inventory (AMI). It can measure overall motivation toward academic achievement through a 20-item inventory that takes approximately 15 minutes to complete. Each item has five response categories: "strongly agree," "agree," "not certain," "disagree," and "strongly disagree." The instrument has four scales (self-efficacy, control, task orientation, task value) and reliability coefficient (internal consistency) was .84, as measured using Cornbrash's alpha. For both three instruments the Amharic version is translated by the researcher himself in collaboration with English language expert (i.e. MA holder in linguistic and litterateur).

A qualitative semi-structured interview was designed and used to explore the conditions and situations that could promote the foster children's psychosocial well-being and its' relationship with attachment and academic achievement motivation. The aim is to allow the respondents to inform the study from their point of view, using their own words and to get supporting idea for the quantitative data. A semi-structured interview guide consisting of themes and questions were prepared in English and then administered in Amharic. The interview administered to selected foster children and foster families. An inductive thematic analysis was used to identify patterns of the semi-structured interview inputs.

\subsection{Data Analysis}

After the data were collected, it was analyzed quantitatively and qualitatively. Quantitatively, the collected data was inserted to SPSS 20 version and analyzed by using mean, standard deviation, and person correlation. For the analysis of the qualitatively data, the researcher relied on inductive thematic analysis. Audio tapes information from interviews feedbacks was transcribed and interpreted.

\subsection{Ethical Consideration}

A letter introducing the objective of the study and maintaining the confidentiality was attached as the cover page of the questionnaire. Participants gave informed consent for participation in the study.

\section{Results}

\subsection{Demographic Characteristics of the Foster Children}

In this part of the study the statistical result of foster children's sexes and educational level are presented. Table 1: Demographic Characteristic of Foster Children $(\mathrm{N}=134)$

\begin{tabular}{llll}
\hline Demographic Variables & & $\mathbf{N}$ & $\mathbf{\%}$ \\
\hline Foster Children Sex & Male & 77 & 57.5 \\
& Female & 57 & 42.5 \\
\hline Foster Children Educational Levels & $1^{\text {st }}$ Level & 19 & 14.2 \\
& $2^{\text {nd }}$ Level & 47 & 35.1 \\
& Preparatory & 33 & 24.6 \\
\hline
\end{tabular}

Table 1 indicates that $77(57.5 \%)$ were males and 57(42.5\%) were females. For those foster children 19(14.2\%) had $1^{\text {st }}$ level education, $47(35.1 \%)$ had $2^{\text {nd }}$ level education, 33(24.6\%) were preparatory students, and $35(26.1 \%)$ had in TVT \& College. 


\subsection{Status of Dependent Variables}

Table 2: Summery Statistics for Variables of the Study $(\mathrm{N}=134)$

\begin{tabular}{lllll}
\hline Variables & Minimum & Maximum & Mean & Std. Deviation \\
\hline Avoidance Attachment & 8.00 & 36.00 & 24.81 & 5.95 \\
Anxious Attachment & 3.00 & 18.00 & 12.15 & 4.07 \\
Emotional Symptom & .00 & 8.00 & 3.64 & 2.08 \\
Conduct Symptom & .00 & 9.00 & 3.58 & 1.87 \\
Hyperactivity Symptom & 1.00 & 10.00 & 4.89 & 1.43 \\
Peer problem Symptom & .00 & 8.00 & 3.79 & 1.50 \\
Pro-social Symptom & 1.00 & 10.00 & 6.27 & 2.27 \\
Total PSWB Symptom & 4.00 & 25.00 & 15.92 & 4.43 \\
Self-efficacy & 13.00 & 26.00 & 20.55 & 3.35 \\
Control & 8.00 & 28.00 & 18.28 & 3.87 \\
Goal orientation & 9.00 & 26.00 & 17.22 & 3.33 \\
Task value & 10.00 & 26.00 & 17.52 & 3.14 \\
Total AAM & 42.00 & 91.00 & 73.58 & 9.44
\end{tabular}

Table 2 show that by the measurement of ECR-RS avoidance attachment minimum score 8 and maximum 36 $(M=24.81 ; S D=5.95)$ and anxious attachment minimum score 3 and maximum $18(M=12.15 ; S D=4.07$; by the measurement of SDQ the foster children's psychosocial wellbeing minimum score 4 and maximum $25(M=15.92$; $S D=4.43)$, and academic achievement motivation minimum score 42 and maximum $91(M=73.58 ; S D=9.44)$.

\subsection{The Relationship among the Variables}

Table 3: Summery of Relationship between Variables

\begin{tabular}{|c|c|c|c|c|c|c|c|c|c|c|c|c|c|c|c|}
\hline Variables & $\stackrel{5}{0}$ & 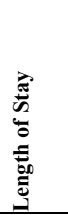 & 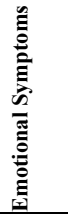 & 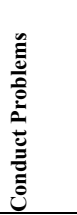 & 氖 & 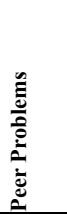 & 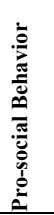 & 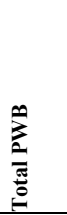 & 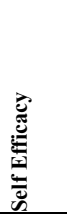 & $\begin{array}{l}\bar{\Xi} \\
\dot{\Xi} \\
\end{array}$ & 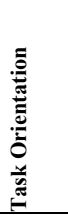 & 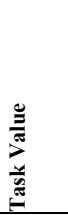 & 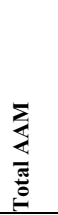 & 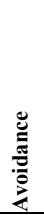 & \\
\hline Length of Stay & $.42^{* *}$ & & & & & & & & & & & & & & \\
\hline Emotional & .13 & .10 & & & & & & & & & & & & & \\
\hline \multicolumn{16}{|l|}{ Symptoms } \\
\hline Conduct Problems & .07 & .06 & $.43 * *$ & & & & & & & & & & & & \\
\hline Hyperactivities & -.14 & -.15 & .01 & -.08 & & & & & & & & & & & \\
\hline Peer Relationship & .01 & -.08 & $.41 * *$ & $.30^{* *}$ & .01 & & & & & & & & & & \\
\hline Pro-social Behavior & -.03 & -.03 & $\begin{array}{l}-.26^{*} \\
*\end{array}$ & $-.20 * *$ & $.22 * *$ & -.07 & & & & & & & & & \\
\hline Total PSWB & .05 & -.00 & $.80 * *$ & $.70^{* *}$ & $.30 * *$ & $.67 * *$ & -.16 & & & & & & & & \\
\hline Self-Efficacy & .07 & -.10 & .00 & -.16 & .05 & -.07 & .08 & -.07 & & & & & & & \\
\hline Control & .06 & -.09 & .14 & .04 & .08 & $.18^{*}$ & -.03 & $.18^{*}$ & $.48^{* *}$ & & & & & & \\
\hline Task Orientation & $-.17 *$ & $-.18^{*}$ & .11 & .07 & $.18^{*}$ & .14 & -.07 & $.19^{*}$ & $.23^{* *}$ & $.47 * *$ & & & & & \\
\hline Task Value & .01 & -.09 & $.32 * *$ & $.30^{* *}$ & .00 & $.18^{*}$ & -.10 & $.34^{* *}$ & -.00 & $.17^{*}$ & $.35^{* *}$ & & & & \\
\hline Total AAM & -.00 & $-.17 *$ & $.20^{*}$ & .08 & .12 & .15 & -.04 & $.23^{* *}$ & $.63^{* *}$ & $.81^{* *}$ & $.75^{* *}$ & $.52 * *$ & & & \\
\hline Avoidance & $-.19^{*}$ & $-.18^{*}$ & -.04 & $-.26^{* *}$ & $.19 *$ & -.05 & .02 & -.09 & .05 & .10 & .13 & .06 & .13 & & \\
\hline \multicolumn{16}{|l|}{ Attachment } \\
\hline Anxiety Attachment & -.08 & -.07 & -.09 & -.10 & $.20 *$ & -.13 & .19 & -.06 & $.18^{*}$ & .04 & $.29 * *$ & -.00 & $.18^{*}$ & .09 & \\
\hline
\end{tabular}

**Correlation is Significant at the 0.01 level (2-tailed)

* Correlation is Significant at the 0.05 level (2-tailed)

As indicated in Table 3 there is significant correlation among the variables (i.e. total PSWB and total AAM, $r(132)=.23 ; \mathrm{p}<0.01$ : task value and total PSWB, $\mathrm{r}=.34 ; \mathrm{p}<0.01$ : control and total $\mathrm{PSWB}, r(132)=.18 ; \mathrm{p}<0.05$ : task orientation and total PSWB, $r(132)=.19 ; \mathrm{p}<0.05$ : total AAM and Anxious attachment, $r(132)=.18 ; \mathrm{p}<.05)$. However, there is no significant correlation among total PSWB and both types of attachment (i.e. Total PSWB with Avoidance and Anxious Attachment).

\section{Discussion}

\subsection{Status of Variables}

The psychosocial wellbeing of the foster children as indicted on the total difficulties result was felled on the 
category of normal symptoms. This is supported by the interpretation score of SDQ (Goodman, 2000). This finding is inconsistent with the finding of other studies conducted on the psychosocial wellbeing of foster children. For example, Gumede (2009) conducted a study on the psychosocial well-being of teenaged orphans; his finding revealed that orphans have psychosocial problems. Also Nasaba et al. (2006) argued that foster children face many psychosocial challenges. And the results of the current study showed that all sub-scales of psychosocial wellbeing are on the normal curve according to Goodman (2000). This indicated that SOS EE BOVPTC foster children have no clear or explicated psychosocial problems with the measurement of SQD. This result has contradiction with the idea of Erik Erikson's theory; development consists of a series of psychosocial crises which is resolved by the maturity of the individual (Erickson, 1950). In general those researchers agreed on the issue of "foster children have psychosocial problems". However, the current study result contradicted to the previous research, this may occur because of the gap between the research finding tools, time-span of years, place or country on the research made, cultural background of participants etc.

In addition to this the results of the findings on attachment revealed that the attachment relationship between the foster children and foster parents are unsecured (i.e. they have above the average avoidance and anxious attachment relationship. If the value of avoidance and anxious attachment relationship increased the value of secured attachment relationship decreased). This finding is consistent with the finding of Stovall-McClough and Dozier (2004). The attachment relationship result of the two sub-scales revealed that their mean scores are in the average range, which means the foster children have some values of avoidance and anxious attachment. This implied that they have not secured attachment relationship. Those who score high on either attachment anxiety or avoidance possess internalized representations of frustrating or unavailable attachment figures and hence suffer from a continuing sense of attachment insecurity (Mikulineer \& Shaver, 2007). It also consistent with the following research findings (Jacobsen et al., 2013, Janet et al., 2006, Stovall-McClough \& Dozier, 2004, and Ponciano, 2010). The overall academic achievement motivation result indicated that, the SOS EE BOVTPC foster children have higher academic achievement motivation on the base of academic achievement inventory interpretations (Athman \& Monroe, 2004). In addition to this the sub-scales of academic achievement motivation result also revealed that they have higher academic achievement motivation. This finding is consistent with the findings of Imaobong et al. (2013). According to Imaobong, the academic achievement motivation has an impact on academic engagement of students. The incredibility of academic achievement motivation leads the student to engage on their academic with full participation. This implies the SOS EE BOVTPC foster children have got some amount of academic achievement motivation from different stakeholders.

According to interviewed respondents (foster children and families) some foster children are aggressive, lack emotional stability, easily irritated, stressed, have anxiety, distracted, have no interest to go to school, do not do their homework rather than continue reading fictions, watching TV/films, staying in bed room for a long time, isolating themselves from any cultural and festival ceremonies that are prepared at home or in the neighborhoods, have lack of socialization; some others are conditional, which means sometimes or when they are moody play with others, participate in the domestic activities, trying to go to school, do their homework, being sociable, participating in different cultural and festival ceremonies etc. However, there are children who have consistent and stable behavior and action such as having good emotional wellness, thinking in different way (they are not rigged/conservative), sociable, having good friends, entertaining in different entertainments, respecting others, have zeal to perform any duty, have good academic motivation and score maximum grade, perfectly perform their homework, have regular school attendances (attending their class carefully), have interest to help others, they consider us as their biological parents and interact without limitation, etc.

\subsection{The Relationship among the Variables}

The present study revealed that foster children psychosocial wellness having a positive relationship with their academic achievement motivation, which mean when the foster child's academic achievement motivation increase their psychosocial wellbeing also increase or vice versa. This implies when children's academic achievement motivation become higher, also their psychosocial wellness become normal or vice versa. However, we cannot say one is the cause of the other. Also, some sub-scales of psychosocial wellbeing have correlation with some subscales of academic achievement motivation (e.g. control with peer relationship, task orientation with hyperactivity, and task value with peer relationship). This result is consistent with the finding of Lindeboom et al. (2010). They explained that the sub-scales of the overall psychosocial wellbeing of foster children have relationship with the academic achievement motivation. According to them among the sub-scales, hyperactivity/inattention has a strong relationship with academic achievement motivation. However, in the current study emotional symptom has a significant correlation with the overall AAM than the other sub-scales.

On the other hand foster children's overall psychosocial wellness has no relationship with both types of attachment (i.e. avoidance and anxious attachment). However, some sub-scales of the total PSWB have correlation with the two attachment types (i.e. avoidance attachment has a negative relationship with conduct problems and positive relationship with hyperactivity; anxious attachment has a positive relationship with hyperactivity). This 
implies when the conduct problems of foster children solved their attachment relationship with their foster family may become normal or when their relationship becomes unsecured the foster children conduct, may become changed, and also when their attachment relationship become anxious they may enter into inattention problems. However, we cannot say one is the cause of the other. This result has consistency with the finding of Sadock and Sadock (2007). According to their finding, persons with avoidance attachment often feel lonely and persons with anxious attachment tend to be obsessed. There is also consistency between the current study and Dexter et al. (2013) and NICHD Early Child Care Research Network (2006) findings. These researchers revealed that secured attachment has been shown to positively influence child social, emotional as well as a cognitive adaptation beyond infancy.

\section{Conclusions}

Based on the major findings of the study, the following conclusions are drawn: The SOS EE BOVTPC foster children have normal psychosocial wellbeing, unsecured attachment and higher academic achievement motivation. Their psychosocial well beings are having a positive relationship with their academic achievement motivation, which means if their psychosocial wellbeing is normal their academic achievement motivation may become higher. In addition the result revealed that foster children psychosocial wellbeing and their attachment have no relationship in general.

From the interviewee response there were risk factors that predict the consequences of foster children's psychosocial wellbeing, attachment and academic achievement motivation. Among these risk factors, physiological barriers, socioeconomic, parental approach to foster children, etc. are considered as the major ones.

\section{Recommendations}

The results of the study indicated that foster children have normal psychosocial wellbeing, unsecured attachment, and higher academic achievement motivation. To enhance the psychosocial wellbeing of foster children, psychosocial support or intervention should be implemented by professionals. The foster parents have also the responsibility to give treatment for their foster children accordingly.

It is better if SOS EE BOVTPC rearranges and organizes the service of guidance and counseling which plays the significant role in preventing, identifying and rehabilitating students who do have lack of psychosocial wellbeing.

In general, taking a comprehensive governmental and non-governmental approach to creating safe fostering environments by enhancing the full continuum of foster children life services, and revising fostering policies as well as caregiving practices that influence communication and collaboration around these issues is good.

\section{Acknowledgments}

First and foremost, I would like to express my deepest gratitude to Professor Habtamu Wondimu my advisor, for his efforts in providing me with relevant advice, critical comments and constructive suggestion throughout the course of my work. Second, I would like to thanks all staffs, foster children, and foster families of SOS Enfants Ethiope, Burayu Orphanage Vocational Training and Production Center. Third,I am grateful to Ato Mitiku Hambisa to his invaluable comments and suggestions. Fourth, I would like to appreciate my sister Aster Demissie for her support, understanding and typing the paper.

\section{References}

AfeworkTsegaye (2013). A comparative study of psychological wellbeing between orphan and non-orphan children in Addis Ababa: The case of three selected schools in Yeka Sub-City.Unpublished MA thesis, Addis Ababa University.

American Academy of Pediatrics (2009). Developmental issues for young children in foster care: PEDIATRICS, 106/5. Retrieved from (http://www. pediatrics.aappublications.org.

Athman, Julic \& Monroe, Martha (2004).The effects of environment-based education on students' achievement motivation.Interpretation, 9,1 .

Bhargava A. (2005). AIDS epidemic and the psychological wellbeing and school participation of Ethiopian orphans. Psychol Health Med 2005; 10(3):263-275.

Delilah, (2013). Adverse childhood experiences and psychosocial well-being of women who were in foster care as children. NURSING RESEARCH \& PRACTICE.

Dexter, C.A.,Wong,K., Stacks,A.M., Beeghiy,M., and Barnett,D. (2013). Parenting and attachment among lowincome africanamerican and caucasian preschoolers. J.Fam.Psychol.27.629-638.

Erikson, E. (1950). Theory of psychosocial development.

Fraley, R. C., Heffernan, M. E., Vicary, A. M., \&Brumbaugh, C. C. (2011). The Experiences in close relationshipsrelationship structures questionnaire: A method for assessing attachment orientations across relationships. Psychological Assessment, 23, 615-625.

Goodman R. (1997). The strengths and difficulties questionnaire: a research note. J Child Psychol Psychiatry, 
38:581-586. doi:10.1007/s00787-004-2005-3.

Gumede, RP. (2009). The psychosocial well-being of the teenaged orphans: Rural community Kwazulu-Natal, Unversity of South Africa, South Africa.

Imaobong D. AkpanPh.D\&Mfonobong E. UmobongPh.D (2013).Analysis of achievement motivation and academic engagement of students in the Nigerian Classroom.Academic Journal of Interdisciplinary Studies. MCSER Publishing, Rome-Italy, 2(3),383-390.

Jacobsen, H., Ivarsson, T., Wentzel-Larsen, T., Smith, L., \& Moe, V. (2013). Attachment security in young foster children: continuity from 2 to 3 years of age. Attachment \& Human Development, DOI: 10.1080/14616734.2013.850102.

Janet Mann \& Molly D. Kretchmar (2006).A disorganized toddler in foster care: Healing and Change From an AttachmentTheory Perspective.

Linda Richter, Geoff Foster and Lorraine Sherr (2006). Where the heart is? Meeting the psychosocial needs of young children in the context of HIV/AIDS.

Lindeboom, M., van den Berg, G., von Hinke Kessler Scholder, S., \&Washbrook, E. (2010). Child mental health problem and youth educational attainment in the UK: Evidence from Avon longitudinal study of parents and children. Conference of epidemiological longitudinal studies in Europe (CELSE): Cyprus.

Mebratu, Eshetu, Ejigu, \&Tesfatsion (2014). Risk factors and resilience: The case of second cycle primary school children in Wolaita Zone, Ethiopia. Journal of Social Science Studies, 1, 2. Retrieved from http://dx.doi.org/10.5296/jsss.v1i2.5920

Mikulincer, M., \& Shaver, P. R. (2007). Attachmentin adulthood: Structure, dynamics, and change. New York: Guilford Press. Retrieved from http://opus.bath.ac.uk/.

Muola J. M. (2010). A study of the relationship between academic achievement motivation and home environment among standard eight pupils.Educational Research and Reviews. 5 (5), pp. 213-217.

Nasaba, R, Defilippi, K, Marston, J, \&Munisi, N. (2006). A clinical guide to support and palliative care for HIV/AIDS in the Sub- Saharan Africa: Care of Children and Adolescent. Retrieved from http://www.biomedcentral.com/1472-698X/14/6.

NICHD Early Child Care Research Network. (2006). Infant-mother attachment classification: risk and protection in relation to changing maternal care giving quality. Dev.Psychol. 42, 38-58.

Ponciano, L. (2010). Attachment in foster care: The role of maternal sensitivity, adoption, and foster mother experience. Child and Adolescent Social Work Journal, 27(2), 97-114.

Roy F. Baumeister\& Kathleen D. Vohs (2007). Encyclopedia of Social Psychology. SAGE Publications India Pvt. Ltd.

Sadock, B.J. \& Sadock V.A. (2007).Synopsis of Psychiatry (10th Ed.). Philadelphia, PA: Lippincott, Williams \& Wilkins.

Sebsibe, Fekadu, \&Molalign (2014). The psychosocial wellbeing of orphan and vulnerable children at orphanage in Gonder Town.Jornal of Public Health and Epidimology. 6, 10, 293-301. Retrieved from http://www.academicjornals.org/JPHE.

Stovall-McClough, K. C., \& Dozier, M. (2004).Forming attachments in foster care: Infant attachment behaviors during the first 2 months of placement.Development and Psychopathology, 16(2), 253-271. 